\title{
Atrioventricular canal mimicking tricuspid atresia: echocardiographic and angiographic features
}

\author{
P SYAMASUNDAR RAO \\ From the Department of Paediatrics, King Faisal Specialist Hospital and Research Centre, Riyadh, \\ Saudi Arabia
}

SUMMARY In a rare case of common atrioventricular canal mimicking tricuspid atresia the clinical, radiographic, electrocardiographic, and $\mathrm{M}$ mode echocardiographic features were indistinguishable from those of classic tricuspid atresia. The cross sectional echocardiographic appearance and right atrial cineangiographic features were distinctive, however, and can be used to discriminate between this anomaly and other types of tricuspid atresia.

\section{Case report}

An eight year old boy was referred with a history of cyanosis since birth and decreased exercise tolerance in the past year. Height and weight were both below the fifth percentile. Physical examination showed cyanosis, clubbing, increased left ventricular impulse, prominent thrill at the left upper sternal border, single second heart sound, a grade $3 / 6$ pansystolic murmur at the left lower sternal border, and a grade $4 / 6$ long systolic murmur at the left upper sternal border.

A chest radiograph showed moderate cardiomegaly, decreased pulmonary vascular markings, and a left aortic arch. The electrocardiogram showed left axis deviation, evidence of left ventricular hypertrophy, and decreased anterior and rightward forces. An M mode echocardiogram showed a large left atrium, markedly enlarged left ventricle with normal left ventricular function, small right ventricle, and a large posterior atrioventricular valve that was continuous with a posterior semilunar valve presumed to be the aortic valve. No echoes were recorded for tricuspid or pulmonary valves. These findings were consistent with classic tricuspid atresia. ${ }^{2}$ A cross sectional echocardiogram showed an ostium primum atrial septal defect, what seemed to be a common atrioventricular valve, and a small right ventricle (fig la and $b$ ). The entrance to the right ventricle seemed to be sealed off by a leaflet of the common atrioventricular valve.

Requests for reprints to Dr P Syamasundar Rao, Division of Pediatric Cardiology, University of Wisconsin-Madison, 600 Highland Avenue, Madison, Wisconsin 53792, USA.
The results of cardiac catheterisation (table) were consistent with classic tricuspid atresia. Selective left ventricular angiography revealed a large, well contracting left ventricle with prompt opacification of the right ventricle via a ventricular septal defect of moderate size. There was valvar and subvalvar pulmonary stenosis. Abnormal attachment of the mitral valve leaflets produced a "goose neck" deformity of the left ventricular outflow tract; this was partially obscured by the opacified right ventricle (fig $2 a$ ). A right atrial cineangiogram showed direct emptying of the contrast material into the left ventricle via the primum atrial septal defect and common atrioventricular valve (fig $2 b$ ). The left atrium was simultaneously opacified, unlike classic tricuspid atresia in which there is sequential opacification of the right atrium, left atrium, and left ventricle. The right ventricle was not directly opacified from the right atrium. The child underwent a right BlalockTaussig shunt which improved systemic arterial oxygen saturation $(84 \%)$.

\section{Discussion}

In this case the right sided component of a common atrioventricular valve occluded the entry of the right atrium into the right ventricle causing left ventricular dominance and underdevelopment of the right ventricle. This anomaly appears to be anatomically distinct from classic forms of tricuspid atresia but produces similar physiological effects. Most cases of tricuspid atresia are of the muscular type $(89 \%){ }^{3}$ Membranous, valvar, and Ebstein's type atresia each cause $3-4 \%$ of cases of tricuspid atresia. ${ }^{3}$ Common atrioventricular canal mimicking tricuspid atresia is 

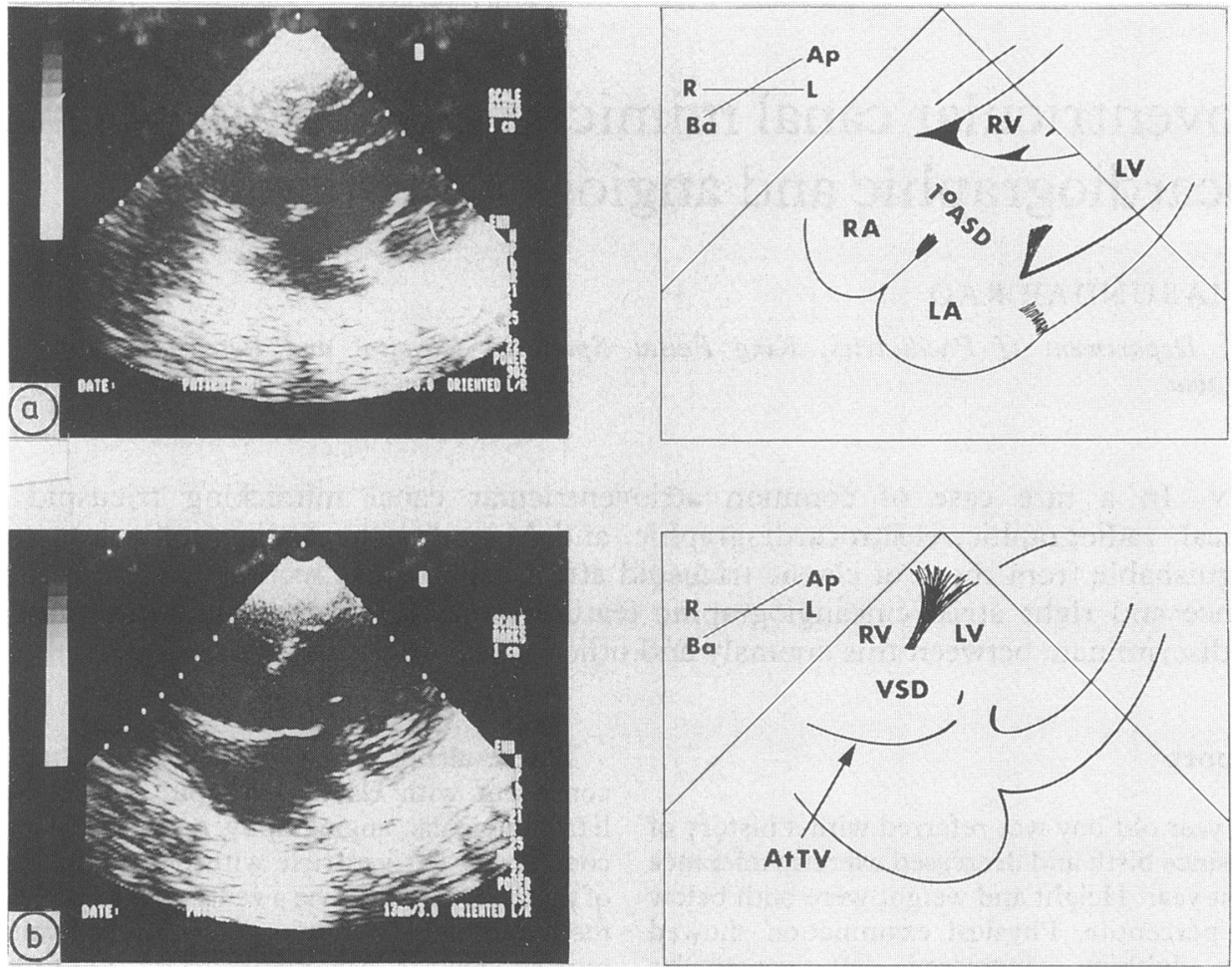

Fig 1 Subcostal four chamber cross sectional echocardiographic views of the heart with an open (a) and almost closed (b) atrioventricular valve. Note the large ostium primum atrial septal defect $(a)$. While it is open the large atrioventricular valve (a) permits emptying of both atria into the left ventricle $(L V)$. The anterior leaflet of the atrioventricular valve occludes the right ventricle $(R V)$ (from the right atrium (RA)) and ventricular septal defect (VSD). When it is closed (b) the atrioventricular valve continues to occlude the RV (At TV) while the VSD allows free communication between the ventricles. $A p$, Apex; Ba, base; $L$, left; $L A$, left atrium; $R$, right.

rarely reported and was only briefly mentioned by Van Praagh. ${ }^{4}$ Such cases were not reported in Van Praagh et al's initial series ${ }^{5}$ or by Anderson et al, Weinberg, Bharati et al, Quero Jimenez, and Ando et al. ${ }^{6-10}$

Table Cardiac catheterisation data

\begin{tabular}{|c|c|c|}
\hline Site & $\begin{array}{l}\text { Oxygen } \\
\text { saturation }(\%)\end{array}$ & $\begin{array}{l}\text { Pressure } \\
\text { (mm Hg) }\end{array}$ \\
\hline $\begin{array}{l}\text { Superior vena cava } \\
\text { Inferior vena cava } \\
\text { Right atrium }\end{array}$ & $\begin{array}{l}29 \\
32 \\
32\end{array}$ & $\begin{array}{l}- \\
\overline{a-10, V-8,}, 5 \\
\text { mean-4.5 }\end{array}$ \\
\hline $\begin{array}{l}\text { Pulmonary vein } \\
\text { Left atrium }\end{array}$ & $\begin{array}{l}95 \\
78\end{array}$ & $\begin{array}{l}-8, V-8, \\
\text { mean-4 }\end{array}$ \\
\hline $\begin{array}{l}\text { Left ventricle } \\
\text { Aorta } \\
\text { Qp:Qs }\end{array}$ & $\begin{array}{l}75 \\
71\end{array}$ & $\begin{array}{l}110 / 6 \\
110 / 65 \text {, mean } 86\end{array}$ \\
\hline
\end{tabular}

The clinical, radiographic, and electrocardiographic features of this case were indistinguishable from those of tricuspid atresia as were the findings on the $M$ mode echocardiogram. The characteristic abnormal, superiorly oriented major QRS vector (left axis deviation) in the frontal plane seen with common atrioventricular canal is a distinguishing feature; however, patients with tricuspid atresia also have similar orientation of the $Q R S$ vector, ${ }^{11}$ but for different electrophysiological reasons. ${ }^{12} 13$

The cross sectional echocardiographic features of tricuspid atresia have been well described. ${ }^{1415}$ In the most common muscular type, a dense band of echoes is seen at the site where the tricuspid valve should be ${ }^{114}$ whereas in the membranous type the atrial floor is much thinner and moves back and forth into the atrial and ventricular cavity during systole and diastole. ${ }^{15}$ i6 In both types the anterior leaflet of the detectable atrioventricular valve is 

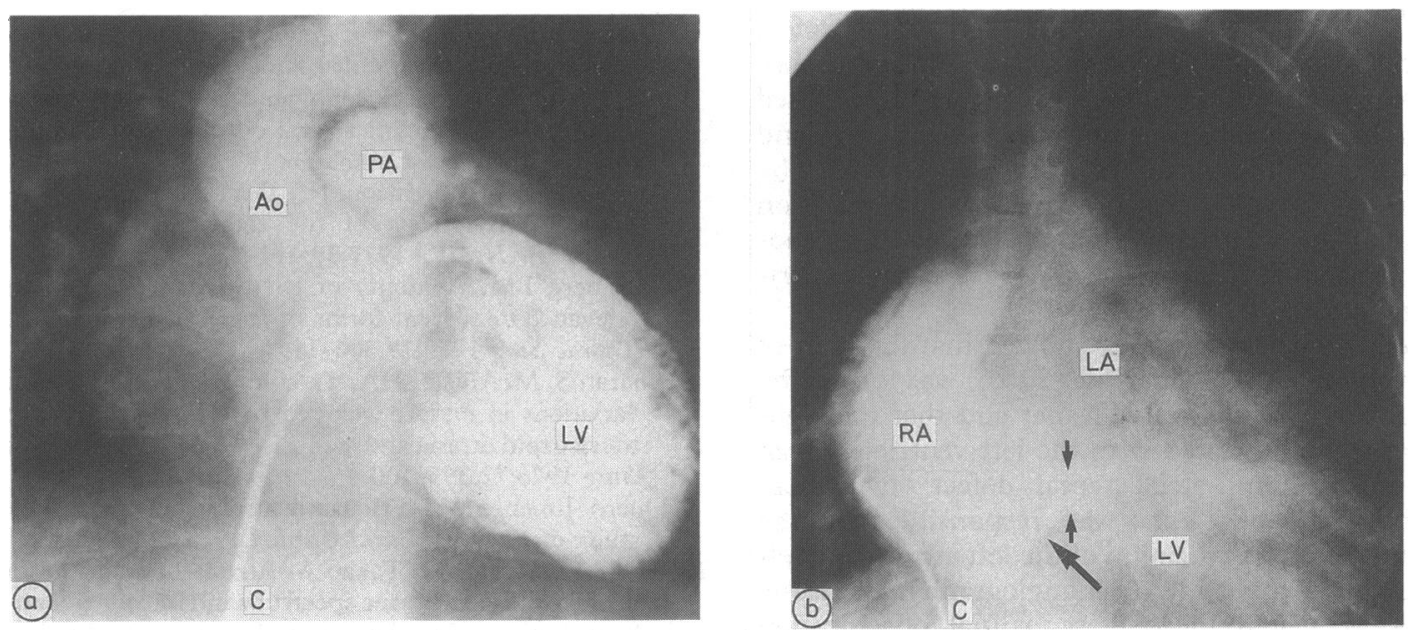

Fig 2 (a) Selected frame from the left ventricular ( $L V$ ) cineangiogram in the posteroanterior view. A large left ventricle is seen with opacification of aorta $(A o)$ and main pulmonary artery $(P A)$; the latter is opacified through the right ventricle. Note the abnormal left ventricular outflow tract which is similar to the "goose-neck" deformity seen in endocardial cushion defects and is presumably related to abnormal attachment of the anterior leaflet of the mitral valve. (b) Right atrial (RA) cineangiographic frame in posteroanterior view. The floor of the right atrium is formed by a leaflet of the atrioventricular valve (large arrow). Note exit of the contrast material via an ostium primum atrial septal defect (small arrows) with opacification of the left ventricle $(L V)$. The left atrium $(L A)$ is only faintly opacified. There was no opacification of the right ventricle. $C$, catheter.

attached to the left side of the interatrial septum ${ }^{14}$ and the echocardiographic crux cordis (produced by the spatial arrangement of the atrial and ventricular septal planes and the plane of the atrioventricular junction) can be demonstrated. ${ }^{15} 16$ In this case the appearance of crux cordis on the cross sectional echocardiogram was abnormal. A large atrioventricular leaflet from the right side occluded the

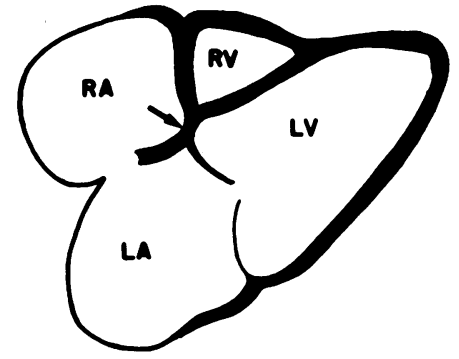

(a) Muscular

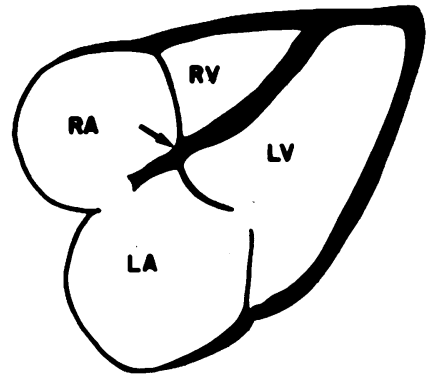

(b) Membranous

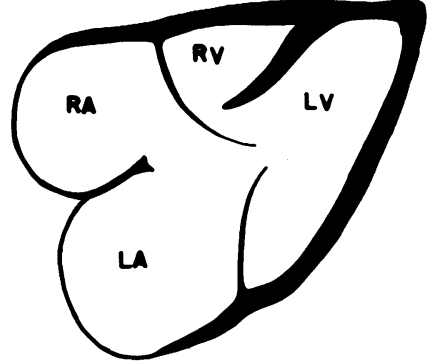

(c) Atrioventricular canal

Fig 3 A drawing showing the cross sectional echocardiographic appearance (subcostal four chamber views) of the muscular, membranous, and atrioventricular canal types of tricuspid atresia. In the muscular type, the atretic tricuspid valve is represented by a thick band of echoes guarding the small right ventricle $(R V)$ while in the membranous type the tricuspid valve is represented by a thin line. In both these the crux of the heart is well visualised. Note the attachment of the anterior leaflet of the detectable atrioventricular valve to the left side of the interatrial septum. The drawing also shows the atrioventricular portion of the interventricular septum (arrows) inferior to (toward left ventricular apex) the attachment of this valve leaflet. In tricuspid atresia of the atrioventricular canal type, the anterior leaflet of the detectable atrioventricular canal is attached to the anterior wall of the heart; it occludes the right ventricle from the right atrium and permits exit of both atria into the left ventricle. An ostium primum atrial septal defect is also shown. Major components of the crux cordis, including the atrioventricular portion of the interventricular septum, are missing. 
right ventricle and the ventricular septal defect when the atrioventricular valve was open (fig la). When the atrioventricular valve (fig $1 \mathrm{~b}$ ) was closed the right ventricle continued to be occluded and could not communicate with the right atrium. The ventricular septal defect provided a communication between the ventricles. Figure 3 shows the echocardiographic appearance of these three types of tricuspid atresia.

Right atrial angiography showed that the floor of the right atrium (large arrow, fig $2 b$ ) was formed by the atrioventricular valve leaflet and that the right atrium communicated with the left ventricle via an ostrium primum atrial septal defect (two small arrows, fig 2b). This was responsible for the simultaneous opacification of the left atrium and left ventricle during right atrial angiography. In classic tricuspid atresia there is sequential opacification of the left atrium and left ventricle.

The cross sectional echocardiographic and angiographic features of common atrioventricular canal mimicking tricuspid atresia distinguish this anomaly from classic tricuspid atresia.

\section{References}

1 Covitz W, Rao PS. Non-invasive evaluation of patients with tricuspid atresia (roentgenography, echocardiography and nuclear angiography). In: Rao PS, ed. Tricuspid atresia. Mt Kisco, New York: Futura, 1982:127-45.

2 Seward JB, Tajik AJ, Hagler DJ, Ritter DG. Echocardiographic spectrum of tricuspid atresia. Mayo Clin Proc 1978;53:100-12.

3 Rao PS. Classification of tricuspid atresia. In: Rao PS, ed. Tricuspid atresia. Mt Kisco, New York: Futura, 1982:41-7.

4 Van Praagh R. Discussion after paper by Vlad P. Pulmonary atresia with intact ventricular septum. In: Barrett-Boyes BG, Neutze JM, Harris EA, eds.
Heart disease in infancy: diagnosis and surgical treatment. London: Churchill Livingstone, 1973:246-9.

5 Van Praagh R, Ando M, Dungan T. Anatomic types of tricuspid atresia: clinical and developmental implications [Abstract]. Circulation 1971;44(suppl II):115.

6 Anderson RH, Wilkinson JL, Gerlis LM, Smith A, Becker AE. Atresia of the right atrioventricular orifice. Br Heart J 1977;39:414-28.

7 Weinberg. PM. Anatomy of tricuspid atresia and its relevance to current forms of surgical therapy. Ann Thorac Surg 1980;29:306-11.

8 Bharati S, McAllister HA, Tatooles CJ, et al. Anatomic variations in underdeveloped right ventricle related to tricuspid atresia and stenosis. $J$ Thorac Cardiovasc Surg 1976;72:383-400.

9 Quero Jimenez M. Tricuspid atresia: an anatomical study of 17 cases. Eur J Cardiol 1975;314:337-48.

10 Ando M, Satomi G, Takao A. Atresia of tricuspid or mitral orifice: anatomic spectrum and morphogenetic hypothesis. In: Van Praagh R, Takao A, eds. Etiology and morphogenesis of congenital heart disease. Mt Kisco, New York: Futura, 1980:421-87.

11 Kulangara RJ, Boineau JP, Moore HV, Rao PS. Electrovectorcardiographic features of tricuspid atresia. In: Rao PS, ed. Tricuspid atresia. Mt Kisco, New York: Futura, 1982:113-26.

12 Durrer D, Roos JP, Van Dam R Th. The genesis of the electrocardiogram of patients with ostium primum defects (ventral atrial septal defects). Am Heart J 1966;71:642-50.

13 Boineau JP, Moore NE, Patterson DF. Relationship between the ECG ventricular activation and the ventricular conduction system in ostium primum ASD. Circulation 1973;48:556-64.

14 Beppu S, Nimura Y, Tamai M, et al. Two-dimensional echocardiography in diagnosing tricuspid atresia. Differentiation from other hypoplastic right heart syndromes and common atrioventricular canal. $\mathrm{Br}$ Heart $J$ 1978;40:1174-83.

15 Rigby ML, Gibson DG, Joseph MC, et al. Recognition of imperforate atrioventricular valves by two dimensional echocardiography. Br Heart J 1982;47:329-36.

16 Magharini A, Azzolina G, Careri J. Anatomy of the echocardiographic crux cordis in the evaluation of the spectrum of atrioventricular valve atresia. Int $J$ Cardiol 1984;5:163-72. 